WellBeing International

WBI Studies Repository

$12-2009$

\title{
Bringing Toxicology into the 21st Century: A Global Call to Action
}

Troy Seidle

Humane Society International

Martin Stephens

The Humane Society of the United States

Follow this and additional works at: https://www.wellbeingintlstudiesrepository.org/acwp_arte

Part of the Bioethics and Medical Ethics Commons, Laboratory and Basic Science Research

Commons, and the Research Methods in Life Sciences Commons

\section{Recommended Citation}

Seidle, T., \& Stephens, M. L. (2009). Bringing toxicology into the 21st century: A global call to action.

Toxicology in Vitro, 23(8), 1576-1579.

This material is brought to you for free and open access by WellBeing International. It has been accepted for inclusion by an authorized administrator of the WBI Studies Repository. For more information, please contact wbisr-info@wellbeingintl.org.

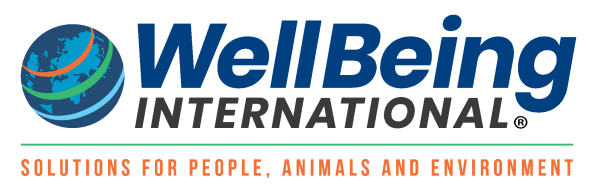




\title{
Bringing toxicology into the 21st century: A global call to action
}

\author{
T. Seidle ${ }^{a, b, c}$, M.L. Stephens ${ }^{c}$ \\ ${ }^{a}$ Humane Society International, Brussels, Belgium \\ ${ }^{\mathrm{b}}$ Humane Society Legislative Fund, Washington, DC, USA \\ ${ }^{\mathrm{c}}$ The Humane Society of the United States, Washington, DC, USA
}

\section{CITATION}

Seidle, T., \& Stephens, M. L. (2009). Bringing toxicology into the 21st century: A global call to action. Toxicology in vitro, 23(8), 1576-1579.

\section{KEYWORDS}

Bioinformatics, computational toxicology, high throughput, in vitro toxicology, risk assessment, systems biology, toxicity pathway

\begin{abstract}
Conventional toxicological testing methods are often decades old, costly and low-throughput, with questionable relevance to the human condition. Several of these factors have contributed to a backlog of chemicals that have been inadequately assessed for toxicity. Some authorities have responded to this challenge by implementing large-scale testing programmes. Others have concluded that a paradigm shift in toxicology is warranted. One such call came in 2007 from the United States National Research Council (NRC), which articulated a vision of "21st century toxicology" based predominantly on non-animal techniques. Potential advantages of such an approach include the capacity to examine a far greater number of chemicals and biological outcomes at more relevant exposure levels; a substantial reduction in testing costs, time and animal use; and the grounding of regulatory decisions on human rather than rodent biology. In order for the NRC's and similar proposals to make a significant impact on regulatory toxicology in the foreseeable future, they must be translated into sustained multidisciplinary research programmes that are well coordinated and funded on a multinational level. The Humane Society is calling for a "big biology" project to meet this challenge. We are in the process of forging an international, multistakeholder consortium dedicated to implementing the NRC vision.
\end{abstract}

\section{Introduction}

The cornerstone of safety evaluations of medicines, food additives, pesticides, cosmetics, consumer products and other chemicals is risk assessment: the process of evaluating the hazardous properties of substances and conditions of exposure to ascertain the likelihood that humans and/or the environment will be adversely affected, and to characterise the nature of the effects which may be experienced (Derelanko, 2002). The conventional risk assessment paradigm consists of four major steps: hazard identification, exposure assessment, dose-response assessment, and risk characterisation.

At present, the hazard identification and dose-response steps in the risk assessment paradigm are heavily focused on the elucidation of gross toxic effects such as acute lethality, organ-related toxicity, birth defects and cancer, as well as the doses at which these effects occur. To this end, toxicity tests using rodents, rabbits, dogs and other animals are relied upon as human surrogates. A number of the test 
methods in mainstream use today were first developed between 60 and 80 years ago (Trevan, 1927; Draize et al., 1944). Using the results of animal tests to predict human health effects involves a number of uncertainties, including whether animal data are relevant to humans, and whether high doses administered to animals are relevant to lower doses to which humans may be exposed. Consequently, a number of "uncertainty factors" of up to 10-fold each may be applied during the risk characterisation step to account for (i) uncertainty in extrapolating animal data to humans, (ii) uncertainty in extrapolating from data obtained in a study with less-than-lifetime exposure to lifetime exposure, (iii) uncertainty associated with extrapolation from animal data when the database is incomplete, (iv) uncertainty in extrapolating from a "LOAEL" rather than a NOAEL, and (v) variation in sensitivity among members of the human population, including between infants/children and adults. Thus, a compounded uncertainty factor of up to 10,000-fold is not unheard of (NRC, 2000).

In recent years, the "3Rs" principle of replacement, reduction and refinement (Russell and Burch, 1959) has gained a higher profile in toxicology due to a convergence of scientific, ethical/animal welfare, financial and legislative imperatives. For instance, many risk assessors would prefer to use mechanistically based empirical data in lieu of conservative extrapolation tools. Legislatively, a timetable for ending all cosmetics testing on animals has been established pursuant to the $7^{\text {th }}$ Amendment of the EUCosmetics Directive, while at the same time, the financial and animal welfare concomitants of applying the data requirements prescribed in the EU's Registration, Evaluation and Authorisation of Chemicals $(\mathrm{REACH})$ regulation to between 30,000 and more than 140,000 chemicals will no doubt be profound (ECHA, 2009). Furthermore, according to one set of national animal use statistics, up to $70 \%$ of the procedures that inflict the greatest animal suffering are undertaken for the purpose of regulatory toxicity testing (CCAC, 2008).

\subsection{Scientific and practical limitations of current approaches}

The current toxicological risk assessment paradigm has a number of limitations, which are largely rooted in the test methods used for hazard identification. Whereas formal validation to demonstrate relevance and reliability has become a prerequisite for regulatory acceptance of newly developed test methods, the great majority of toxicological studies in use today predate the existence of modern validation criteria (Hartung et al., 2004) and have never been scrutinised in such a systemic and rigorous manner (Balls, 2004). However, the published literature is rife with case studies in which data from non-validated animal tests have been found to be poor predictors of real-world human effects (Basketter et al., 2004; NRC, 2006; Ekwall et al., 1998; Stanton and Spear, 1990; Ennever et al., 1987; Freeberg et al., 1986; Haseman, 1983; Salsburg, 1983; Weil and Scala, 1971).

Some discoveries of interspecies differences come with grave consequences, as in the case with the clinical drug trial for TGN 1412, which nearly cost the lives of human study participants (Bhattacharya and Coghlan, 2006). In the pharmaceutical sector, it is reported that $92 \%$ of drug candidates are abandoned during clinical trials for reasons including inefficacy and the discovery of toxic effects in humans that were not identified in preclinical animal testing (FDA, 2004). The adequacy of conventional test methods has likewise been questioned in relation to sensitivity to endocrine-mediated adverse effects (EDSTAC, 1998), as well as for the hazard and risk assessment of nanoscale particles (SCENIHR, 2006).

Additionally, the low-throughput and high cost of conventional toxicity testing methods and strategies limits their desirability and practical utility, both in general terms (Carmichael et al., 2006; McDougall, 2003), and particularly as tools for responding to political and legislative mandates for the safety assessment of an increasingly large number of chemicals, mixtures and co-exposures. These factors have contributed to a daunting backlog of tens of thousands of chemicals and mixtures that have yet to 
be adequately assessed for their effects on human health and the environment - a situation that is compounded by the ongoing addition to the global marketplace of hundreds of new substances each year (GAO, 2005).

In contrast, whereas available 3R methods generally offer certain advantages in terms of increased mechanistic relevance and/or reduced costs, testing time and animal use (Ayres et al., 2008; Hollinger and Derelanko, 2002), they too have limitations. For example, most in vitro methods lack biotransformation capacity and cannot account for kinetic factors (i.e. absorption, distribution and elimination), which impedes reliable extrapolation of cellular/tissue-response data across several levels of biological organization to derive organism-level values such as NOAELs (ECHA, 2008). Another consideration is the exorbitant time and cost involved in the development, validation and regulatory acceptance of 3 Rs methods according to conventional procedures (EPAA, 2008).

\subsection{Emerging technologies}

The past two decades have seen unprecedented scientific and technological advances, including the birth of functional genomics, the explosive growth of computing power and computational biology/bioinformatics, the establishment of robotic platforms for high throughput chemical screening, and most recently, the sequencing of the human genome. Together, these advances have triggered a revolution in molecular biology, as well as the establishment of specialised research centres and collaborative initiatives across the EU and globally to explore and harness these new opportunities. One prominent example is the Netherlands Genomics Initiative, which operates a network of large-scale research centres and consortia that work on targeted programmes designed to generate societal and economic value from genomics (NGI, 2008). Another example is the US National Institutes of Health Chemical Genomics Center (NCGC), which has developed an ultra-high throughput, in-house testing platform capable of profiling more than 1400 substances at 15 concentrations in 200 mechanistic assays in as little as two weeks (C. Austin, personal communication, 09.02.08). These and similar initiatives are generating vast amounts of data concerning the functioning of living organisms at the level of genes, proteins, metabolites and other cellular and biochemical components (MLI, 2008). Given the promise of these new technologies, the International Life Sciences Institute (ILSI, 2008) has already convened an expert working group to explore issues germane to their regulatory acceptance and use in human health risk assessment.

\subsection{Calls for a global paradigm shift}

Some observers have assessed the scientific, ethical and practical limitations of conventional testing and risk assessment methods and called for nothing less than a fundamental paradigm shift in regulatory toxicology. As far back as 1980, Nobel laureate Dr. Joshua Lederberg wrote: "It is simply not possible with all the animals in the world to go through new chemicals in the blind way that we have at the present time and reach credible conclusions about the hazards to human health. We are at an impasse...with deep scientific roots and we had better do something about it" (Lederberg, 1980). Similar sentiments were recently expressed by a group of eminent scientists convened by the EPAA (2008), who concluded that: "Truly innovative approaches to testing and risk assessment are needed for safe development of new products without recourse to animal experiments."

\section{Discussion}

A variety of proposals have been put forward in recent years to modernise aspects of toxicological testing and/or risk assessment (e.g. FDA, 2004; NTP, 2004; Carmichael et al., 2006; NRC, 2007; Collins et al., 
2008; EPAA, 2008); however, one in particular stands out as providing a truly groundbreaking perspective. The 2007 report Toxicity Testing in the 21st Century: A Vision and a Strategy by the US National Research Council (NRC) envisions a not-so-distant future where virtually all routine toxicity testing will be conducted in human cells or cell lines in vitro by evaluating perturbations of cellular responses in a suite of toxicity pathway assays using rapid robotic-assisted methodologies (Andersen and Krewski, 2009).

The vision articulated by the NRC represents a fundamental departure from the conventional highdose/apical-effect paradigm in animals. Among its key attributes is an uncompromising focus on human, rather than rodent, biology, as well as the consideration of biological perturbations at exposure levels that are environmentally relevant.

The NRC vision is predicated on the aforementioned advances in molecular and computational biology. By integrating these tools and technologies, it becomes possible to mine large libraries of biological and chemical toxicity data, from which "maps" of cellular pathways and responses can be generated. An initial effort along these lines has already begun under the auspices of the US Environmental Protection Agency (EPA) ToxCastTM initiative (EPA, 2008), as well as through the "Tox21" collaboration between the EPA, NCGC, and US National Toxicology Program (HHS and EPA, 2008; Collins et al., 2008).

As toxicity pathways are identified, in vitro assays can be developed to study chemical interactions at key cellular and molecular targets within a pathway. Such assays may then be scaled up to high throughput platforms using robotic automation in order to test large numbers of compounds (Andersen and Krewski, 2009). A parallel goal will be to broaden the suite of in vitro assays to encompass the as-yetundetermined number of critical toxicity pathways present in the human body. Computational systems biology models will also be needed to describe the "circuitry" underlying each toxicity pathway as a basis for creating biologically based dose-response models. Subsequently, dose-dependent transition studies for sequential pathway activation can be undertaken to understand the linkage to cell- and tissue-level responses, i.e. the relationship between perturbations and adversity.

Ultimately, the NRC vision offers the promise of a more scientifically sound approach to risk assessment-and one with the capacity to examine a much larger number of chemicals, mixtures and biological outcomes at more relevant exposure levels than would be possible using conventional approaches; greater human relevance; reduced time, costs and animal use; and potentially, an end to animal testing altogether.

\subsection{From roadmap to reality: bringing the vision to life}

Implementation of the NRC vision of 21st century toxicology will require a large-scale, highly co-ordinated and well-funded interdisciplinary and international research effort on par with the Human Genome Project of the 1990s. The NRC itself has projected that the cost of implementing its vision could be on the order of hundreds of millions.

The Humane Society is heavily invested in seeing the NRC vision brought to fruition. One of us (MLS) was a member of the committee that produced the 2007 vision and roadmap report, and was part of the peer review panel for the new EPA (2009) toxicity testing strategic plan. Consistent with our long history of building partnerships for progress, we are assembling a multi-stakeholder consortium to promote dialogue and collaboration among corporate, academic and NGO leaders, and to act as a unifying vehicle for outreach to policymakers, regulators, business leaders and the public at large to encourage their support for and investment in the NRC vision. Already six multinational companies representing the 
chemical, consumer product and pharmaceutical sectors have joined this "Human Toxicology Project Consortium," and discussions are ongoing with other corporate, academic and public interest organisations regarding potential membership in the consortium.

Additionally, the British office of Humane Society International - in partnership with the Flemish Institute for Technological Research (VITO) and the Freie Universität Berlin - is presently in negotiations with the European Commission to spearhead a multi-year, pan-European co-ordination project under the 7th EU Framework Programme for Research and Technology Development. The proposed "AXLR8" project aims to establish a standing committee of leading scientists, host workshops and expert meetings to help shape future EU research activities in this area, and undertake pro-active outreach to the regulatory, scientific and other key stakeholder communities with the goal of accelerating the transition to a toxicity pathway-based paradigm for risk assessment.

Individuals and organisations interested in moving this process forward are invited to join with us in promoting the NRC vision and working towards its timely implementation. While ambitious in its scope, the success of the Human Genome Project has already proven that a similarly daunting task is achievable if there is sufficient will. The technology is for the most part already available; we now need to assemble the remaining tools for creating a new risk assessment paradigm that determines responses of human cells to chemical stressors and estimates the exposure conditions under which these responses are likely to have adverse consequences. And with a united, multi-stakeholder effort, it should be possible to revolutionise the field of toxicology over the course of the next decade or more for the benefit of science, public health, animal welfare and corporate interests alike.

\section{References}

Andersen, M., Krewski, D., 2009. Toxicity testing in the 21st century: bringing the vision to life. Toxicological Sciences 107, 324-330.

Ayres, J.G., Borm, P., Cassee, F.R., Castranova, V., Donaldson, K., Ghio, A., Harrison, R.M., Hider, R., Kelly, F., Kooter, I.M., Marano, F., Maynard, R.L., Mudway, I., Nel, A., Sioutas, C., Smith, S., Baeza-Squiban, A., Cho, A., Duggan, S., Froines, J., 2008. Evaluating the toxicity of airborne particulate matter and nanoparticles by measuring oxidative stress potential - a workshop report and consensus statement. Inhalation Toxicology 20,75-99.

Balls, M., 2004. Are animal tests inherently valid? Alternatives to Laboratory Animals 32 (Suppl. 1), 755758.

Basketter, D.A., York, M., McFadden, J.P., Robinson, M.K., 2004. Determination of skin irritation potential in the human 4-h patch test. Contact Dermatitis 51, 1-4.

Bhattacharya, S., Coghlan, A., 2006. One drug, six men, disaster.... New Scientist 189 (2544), 10-11.

Carmichael, N.G., Barton, H.A., Boobis, A.R., Cooper, R.L., Dellarco, V.L., Doerrer, N.G., Fenner-Crisp, P.A., Doe, J.E., Lamb-IV, J.C., Pastoor, T.P., 2006. Agricultural chemical safety assessment: a multisector approach to the modernization of human safety requirements. Critical Reviews in Toxicology 36, 1-7.

CCAC (Canadian Council on Animal Care), 2008. Facts and Figures - CCAC Animal Use Survey (Table III: Number of Animals Used per Purpose of Animal Use and Category of Invasiveness). $<$ http://www.ccac.ca/en/Publications/New_Facts_Figures/intro.htm> (accessed 31.10.08).

Collins, F.S., Gray, G.M., Bucher, J.R., 2008. Toxicology. Transforming environmental health protection. Science 319, 906-907.

Derelanko, M.J., 2002. Risk Assessment. In: Derelanko, M.J., Hollinger, M.A. (Eds.), Handbook of Toxicology, second ed. CRC Press, London, p. 1003. 
Draize, J.H., Woodard, G., Calvery, H.O., 1944. Methods for the study of irritation and toxicity of substances applied topically to the skin and mucous membranes. Journal of Pharmacology and Experimental Therapeutics 82, 377-390.

ECHA (European Chemicals Agency), 2008. Guidance on Information Requirements and Chemical Safety Assessment. Chapter R.7a: Endpoint Specific Guidance. $<$ http://reach.jrc.it/docs/guidance_document/information_requirements_r7a_en.pdf?vers=20_08_ 08> (accessed 26.05.09).

ECHA, 2009. List of Pre-registered Substances. <http://apps.echa.europa.eu/preregistered/preregistered-sub.aspx> (accessed 30.06.09).

EDSTAC (US Environmental Protection Agency Endocrine Disruptor Screening and Testing Advisory Committee), $1998 . \quad$ EDSTAC Final Report. <http://www.epa.gov/endo/pubs/edspoverview/finalrpt.htm> (accessed 26.05.09).

Ekwall, B., Barile, F.A., Castano, A., Clemendson, C., Clothier, R.J., Dierickx, P., Ekwall, B., Ferro, M., Fiskesjö, G., Garza-Ocañas, L., Gómez-Lechón, M.J., Gülden, M., Hall, T., Isomaa, B., Kahru, A., Kerszman, G., Kristen, U., Kuniamoto, M., Kärenlampi, S., Lewan, L., Loukianov, A., Ohno, T., Persoone, G., Romert, L., Sawyer, T.W., Shrivastava, R., Segner, H., Stammati, A., Tanaka, N., Valentino, M., Walum, E., Zucco, F., 1998. MEIC evaluation of acute systemic toxicity. Part VI. The prediction of human toxicity by rodent LD50 values and results from 61 in vitro methods. Alternatives to Laboratory Animals 26 (Suppl. 2), 617-658.

Ennever, F.K., Noonan, T.J., Rosenkranz, H.S., 1987. The predictivity of animal bioassays and short-term genotoxicity tests for carcinogenicity and noncarcinogenicity in humans. Mutagenesis 2, 73-78.

EPA (US Environmental Protection Agency), 2008. ToxCastTM Program: Predicting Hazard, Characterizing Toxicity Pathways, and Prioritizing the Toxicity Testing of Environmental Chemicals. http://www.epa.gov/ncct/toxcast/index.html (accessed 26.05.09).

EPA, 2009. The US Environmental Protection Agency's Strategic Plan for Evaluating the Toxicity of Chemicals. <http://www.epa.gov/osa/spc/toxicitytesting/docs/toxtest_strategy_032309.pdf> (accessed 26.05.09).

EPAA (European Partnership on Alternative Approaches to Animal Testing), 2008. New Perspectives on Safety. Workshop Report. EPAA, Brussels.

FDA (US Food and Drug Administration), 2004. Challenge and Opportunity on the Critical Path to New Medical Products. <http://www.fda.gov/oc/initiatives/criticalpath/whitepaper.html> (accessed 31.10.08).

Freeberg, F.E., Hooker, D.T., Griffith, J.F., 1986. Correlation of animal eye test data with human experience for household products: an update. Journal of Toxicology - Cutaneous and Ocular Toxicology 5, 115-123.

GAO (US Government Accounting Office), 2005. Chemical Regulation: Options Exist to Improve EPA's Ability to Assess Health Risks and Manage Its Chemical Review Program. <http://www.gao.gov/products/GAO-05-458> (accessed 31.10.08).

Hartung, T., Bremer, S., Casati, S., Coecke, S., Corvi, R., Fortaner, S., Gribaldo, L., Halder, M., Hoffmann, S., Janusch-Roy, A., Prieto, P., Sabbioni, E., Scott, L., Worth, A., Zuang, V., 2004. A modular approach to the ECVAM principles on test validity. Alternatives to Laboratory Animals 32, 467-479.

Haseman, J.K., 1983. A reexamination of false-positive rates for carcinogenesis studies. Fundamental and Applied Toxicology 3, 334-339.

HHS and EPA (US Department of Health and Human Services and US Environmental Protection Agency), 2008. Memorandum of Understanding on High Throughput Screening, Toxicity Pathway Profiling, and Biological Interpretation of Findings.

$<$ <ttp://ntp.niehs.nih.gov/files/ntpncgcepamou.pdf> (accessed 31.10.08). 
Hollinger, M.A., Derelanko, M.J., 2002. Miscellaneous Information. In: Derelanko, M.J., Hollinger, M.A. (Eds.), Handbook of Toxicology, second ed. CRC Press, London, pp. 1327-1328.

ILSI (International Life Sciences Institute), 2008. The Use of "Omics" in Human Health Risk Assessment. $<$ http://rsi.ilsi.org/Omics.htm> (accessed 26.05.09).

Lederberg, J., 1980. A challenge for toxicologists. Chemical Engineering News 1, 5. McDougall, P., 2003. The Cost of New Agrochemical Product Discovery, Development and Registration in 1995 and 2000. Final Report. European Crop Protection Association, Brussels.

MLI (US National Institutes of Health Molecular Libraries Initiative), 2008. PubChe - Public Cheminformatics Database Statistics as of November 2008. <https://mli.nih.gov/mli/pubchem> (accessed 26.05.09).

NGI (Netherlands Genomics Initiative), 2008. NGI Genomics Centres. <http://www.genomics.nl> (accessed 31.10.08).

NRC (US National Research Council), 2000. Scientific Frontiers in Developmental Toxicology and Risk Assessment. National Academy Press, Washington, DC. p. 12.

NRC, 2006. Toxicity Testing for Assessment of Environmental Agents. National Academy Press, Washington, DC.

NRC, 2007. Toxicity Testing in the 21st Century. A Vision and a Strategy. National Academy Press, Washington, DC.

NTP (US National Toxicology Program), 2004. A National Toxicology Program for the 21st Century. $<$ http://ntp.niehs.nih.gov/files/NTPrdmp.pdf> (accessed 26.05.09).

Russell, W.M.S., Burch R.L., 1959. The Principles of Humane Experimental Technique. <http://altweb.jhsph.edu/publications/humane_exp/het-toc.htm> (accessed 31.10.08).

Salsburg, D., 1983. The lifetime feeding study in mice and rats - an examination of its validity as a bioassay for human carcinogens. Fundamental and Applied Toxicology 3, 63-67.

SCENIHR (Scientific Committee on Emerging and Newly Identified Health Risks), 2006. Modified Opinion (after Public Consultation) on the Appropriateness of Existing Methodologies to Assess the Potential Risks Associated with Engineered and Adventitious Products of Nanotechnologies. <http://ec.europa.eu/health/ph_risk/committees/04_scenihr/docs/scenihr_o_003b.pdf> (accessed 31.10.08).

Stanton, M.E., Spear, L.P., 1990. Workshop on the qualitative and quantitative comparability of human and animal developmental neurotoxicity - Workgroup 1 report. Neurotoxicology and Teratology $12,261-267$.

Trevan, J.W., 1927. The error of determination of toxicity. Proceedings of the Royal Society (London), Series B 101, 483-514.

Weil, C.S., Scala, R.A., 1971. Study of intra- and interlaboratory variability in the results of rabbit eye and skin irritation tests. Toxicology and Applied Pharmacology 19, 276-360. 